HEALTH PSYCHOLOGY REPORT · VOLUME 7(3), 2019 ORIGINAL ARTICLE
Agnieszka Trawicka

$1 \cdot \mathrm{A}, \mathrm{B}, \mathrm{D}, \mathrm{E}, \mathrm{F}$

Aleksandra

Lewandowska-Walter (D)

$2 \cdot \mathrm{A}, \mathrm{C}, \mathrm{D}, \mathrm{E}, \mathrm{F}$

Marta Bogdanowicz (D)

$3 \cdot A, D, E, G$
Lidia

Woźniak-Mielczarek (1)

$1 \cdot \mathrm{B}, \mathrm{D}, \mathrm{E}$

Dorota

Janikowska-Hotoweńko

$4 \cdot \mathrm{D}, \mathrm{E}, \mathrm{F}$

Magdalena

Bilicka-Siewert

$5 \cdot \mathrm{D}, \mathrm{E}, \mathrm{F}$

\title{
Internalizing and externalizing behaviors in chronically ill adolescents in the context of family system functioning
}

\section{BACKGROUND}

Diagnosis of chronic illness, which constitutes a lifethreatening situation such as in Marfan syndrome or disease with periods of remission and severity such as in juvenile idiopathic arthritis (JIA), leads to problems with the functioning of the adolescent and the whole family system. Therefore the aim of the study was to determine the differences in severity of internalizing and externalizing problems and in the perception of the family system between adolescents with Marfan syndrome, with JIA, and without chronic disease, as well as to determine whether characteristics of the family system are associated with externalizing and internalizing behaviors in those groups.

\section{PARTICIPANTS AND PROCEDURE}

The study involved three groups of adolescents: 1) with Marfan syndrome $(n=25), 2)$ with JIA $(n=29)$, and 3) without chronic illness $(n=20)$. We used the adolescent version of the Child Behavior Checklist (CBCL) Youth Self-Report (YSR) and the Family Assessment Scale.

\section{RESULTS}

Our results indicated that adolescents with Marfan syndrome have similar scores compared to adolescents with- out illness on all subscales concerning both internalizing and externalizing behaviors, as well as the family system's characteristics. Compared to adolescents with JIA, adolescents with Marfan syndrome had lower scores on externalization symptoms and Attention Problems and they also perceive their families as less balanced. Additionally, in the perception of adolescents with Marfan syndrome and with JIA the weaker the family bond, the stronger the intensity of externalizing behaviors.

\section{CONCLUSIONS}

Although in the light of our novel research, adolescents with Marfan syndrome do not present behavioral problems different from healthy peers, it is worth continuing such research in order to verify the results. Adolescents with JIA present more externalizing behaviors than peers without chronic illness, which is consistent with some previous research. Research on families of an adolescent child with Marfan and JIA are quite novel and they should be continued.

\section{KEY WORDS}

juvenile idiopathic arthritis; adolescence; Marfan syndrome; family system; externalizing and internalizing behaviors

ORganization - 1: Department of Pediatric Cardiology and Congenital Heart Diseases, Medical University of Gdansk, Gdansk, Poland · 2: Institute of Psychology, University of Gdansk, Gdansk, Poland · 3: SWPS University of Social Sciences and Humanities, Sopot Campus, Poland · 4: Prof. Tadeusz Bilikiewicz Psychiatric Hospital in Gdansk, Poland · 5: Jadwiga Titz-Kosko Provincial Rheumatology Clinic in Sopot, Poland

aUthors' Contributions - A: Study design - B: Data collection - C: Statistical analysis · D: Data interpretation .

E: Manuscript preparation · F: Literature search · G: Funds collection

CORRESPonding AUthor - Aleksandra Lewandowska-Walter, Ph.D., Institute of Psychology, University of Gdansk,

4 Bażyńskiego Str., 80-952 Gdansk, Poland, e-mail: psyalw@ug.edu.pl

TO CITE THIS ARTICLE - Trawicka, A., Lewandowska-Walter, A., Bogdanowicz, M., Woźniak-Mielczarek, L., Janikowska-

Hołoweńko, D., \& Bilicka-Siewert, M. (2019). Internalizing and externalizing behaviors in chronically ill adolescents

in the context of family system functioning. Health Psychology Report, 7(3), 213-228. https://doi.org/10.5114/

hpr.2019.87934

RECEIVED 19.03.2019 · REVIEWED 16.07.2019 • ACCEPTED 05.08.2019 · PUBLISHED 13.09.2019 


\section{BACKGROUND}

In recent years the population of chronically ill children and adolescents has increased. Studies on general populations show that $10-20 \%$ of children live with a chronic illness. In this population, the frequency of psychiatric problems seems higher than in the general population (15\%; Marcelli, 2013). Undertaking research on the functioning of a child with chronic illness in a wider context, through - among others

Agnieszka

Trawicka,

Aleksandra LewandowskaWalter,

Marta

Bogdanowicz, Lidia WoźniakMielczarek, Dorota JanikowskaHołoweńko, Magdalena Bilicka-Siewert
- taking into account the specific nature of the family system, seems to be an important task due to the current need to design and plan actions in the field of prevention of mental disorders among children and adolescents with chronic illnesses (Rolland, 1987, 1999). A holistic approach towards health obliges us to reflect on the chronically ill children in the context of psychosocial aspects of their functioning and including - in the process of understanding their situation - the role of family functioning. Interdisciplinary analyses which include the effectiveness of actions directed at chronically ill children show that a healthy family can be an important facilitator of the child's rehabilitation. Dysfunctional family functioning can have a negative effect on the physical and emotional state of the children, as well as on the course of treatment. It seems that the relationship between the functioning of a child with somatic illness and family functioning were not sufficiently researched, especially in the case of rare diseases; and the contradictory conclusions from different scientific reports indicate that there is a need for a multifaceted approach to the discussed issue (Zubrzycka, 2014).

The research project deals with the issues related to the psychosocial functioning of adolescents with Marfan syndrome and their families. Diagnosis of a chronic illness in an adolescent, which constitutes a life-threatening situation, leads to severe stress being experienced by the child and members of the child's family. Subsequent participation in the treatment process requires considerable psychological resources, both from the sick person as well as their parents and siblings. The comparative groups in the project included a group of young people without any chronic disease and young people with juvenile idiopathic arthritis (JIA), which is also a chronic disease, but it limits the functioning of a sick person to a lesser extent and, above all, it does not pose a threat to life.

\section{THE SPECIFICITY OF CHRONIC DISEASES AMONG ADOLESCENTS WITH MARFAN SYNDROME AND JUVENILE IDIOPATHIC ARTHRITIS}

Chronic diseases are a group of diseases that differ in their etiology, symptomatology, severity and multiple other variables. The most important aspects of chronic illnesses are their gradual development, the beginning point that is difficult to determine and often the inability to get completely cured. Chronic disease is perceived as a chronic stressor - its beginning is difficult for the family, and its gradual character puts numerous challenges and tasks in front of the sick person and their family in each successive phase of the diseases development (Ziarko, 2014; Rolland, 1987, 1999). Chronic illness is also associated with lowering the quality of life, changes in the previous forms of activity, the roles performed in the family, and - from a wider perspective - in the society, and the necessity to adjust one's life plans (Heszen, 2005). There are also those chronic diseases which are associated with more stable functioning and those in which there is a high risk of exacerbation of symptoms or even threat to life (Rolland, 1999).

Marfan syndrome is a chronic life-threatening disease. It is a genetically conditioned autosomal dominant disorder, a disease of the connective tissue caused by a mutation in the fibrillin gene (Dietz et al., 1991). Marfan syndrome involves numerous organs and systems. The classic triad of symptoms includes anomalies in the skeletal system, the cardiovascular system and the visual organ (Keane \& Pyeritz, 2008). Changes in the respiratory system, nervous system, skin layers, muscles and adipose tissue are less frequent (Dean, 2007). Marfan syndrome is characterized by a very diverse clinical picture, even when it occurs among relatives. The symptoms of the syndrome may be present already in the neonatal period, but among most patients they manifest themselves in later childhood or early adulthood. The most recognizable are skeletal abnormalities the appearance of excessive linear growth of long bones among the patients, which is responsible for excessive growth and numerous abnormalities in the skeletal system, such as spider fingers, scoliosis, flat feet, chest wall deformities or abnormally long upper and lower limbs compared to the trunk (Erkula, Jones, Sponseller, Dietz, \& Pyeritz, 2002; Scherer, Arn, Dressel, Pyeritz, \& Haller, 1988; Glard et al., 2008). Regarding the eyes, the most common irregularity is a high degree of short-sightedness, which often progresses rapidly during the growth period (Maumenee, 1981). Lens subluxation - that is, the fact that the lens is moved to a non-anatomic position - is also very characteristic (Nemet, Assia, Apple, \& Barequet, 2006). Patients with Marfan syndrome also have a greater risk of retinal detachment, glaucoma and cataracts. However, the most serious anomalies concern the cardiovascular system and they are responsible for shortening the life expectancy of patients with Marfan syndrome (Adams \& Trent, 1998; Jondeau et al., 2012). The main cause of death among them is rupture and dissection of aortic aneurysms. Abnormalities in the circulatory system usually give no symptoms for a long time, 
and if untreated can lead to premature death. Surgery of the augmented aorta carried out in advance can significantly extend the life of patients. This is why proper diagnosis of Marfan syndrome and monitoring of changes in the circulatory system are so important.

In contrast to Marfan syndrome, for patients with JIA there is no risk of sudden death. However, in the course of the illness there are periods of exacerbation of the symptoms and periods when the symptoms are mild (Rolland, 1987). Juvenile idiopathic arthritis is the most common rheumatic illness occurring during development. It is an autoimmune disease of the connective tissue, which leads to progressive impairment of joint function and periarticular structures (Bolanowski \& Wrzosek, 2007). Juvenile idiopathic arthritis is an iatrogenic disease in which the symptoms last for at least six weeks and first appear before the age of 16 (TuszkiewiczMisztal, Smolewska, Postępski, \& Olesińska, 2014). The etiology of JIA is unknown. It is assumed that the occurrence of the disease is linked to impaired immune response, genetic factors, past viral and bacterial diseases, and hormonal factors. There are three forms of JIA, and the diagnosis is based on the clinical symptoms occurring in the first six months of the disease - a generalized (systemic) form, a lowgrade (oligoarthritis) form, and polyarticular arthritis. Regarding the clinical symptoms of JIA, the most common ones are swelling, exudations, painfulness and limitation of mobility, which as a consequence, during the progression of the disease, lead to joint distortions, muscular atrophy as well as disability. The early age of onset is associated with a greater tendency to generalized symptoms of the disease, growth disorders and the occurrence of developmental changes. In young children, regardless of the JIA subtype, the disease has a more dramatic and active course, while later on, the course of the disease is similar to that observed in adults, that is, it is limited to the locomotor system. In comparison to people with rheumatoid arthritis (RA), people who were diagnosed as children with JIA, after sixteen years of age are less likely to experience destructive changes in the locomotor system but are more often diagnosed with developmental disorders. The course of JIA is chronic with periods of exacerbation and remission, and the therapeutic prognosis depends on numerous factors. The prognosis is influenced by the stage of the disease, its severity, as well as psychosocial factors, including the functioning of the family of the child with JIA. Treatment is symptomatic and adapted individually to the child depending on the clinical subtype and the inflammatory process. Treatment of a child with JIA can last for many years and it should be carried out by a rheumatologist in cooperation with doctors of other specialties such as orthopedists, physiotherapists, ophthalmologists and psychologists. The main goal of the treatment is to reduce the overall inflammatory-immunological activity, to slow down or stop the progressive dysfunction of the musculoskeletal system, sight or internal organs and to prevent relapse (TuszkiewiczMisztal et al., 2014).

\section{PSYCHOSOCIAL FUNCTIONING IN ADOLESCENTS WITH MARFAN SYNDROME AND ADOLESCENTS WITH JUVENILE IDIOPATHIC ARTHRITIS}

Currently most research on chronic diseases includes psychological variables. Psychological factors can have different effects on somatic diseases and human dysfunctions - they exacerbate existing diseases, as in the case of rheumatic diseases (Heszen \& Sęk, 2007) and may be a risk factor in cardiovascular diseases.

In the case of people with Marfan syndrome, limited physical activity causes a number of difficulties related to everyday life and affects their quality of life and psychosocial functioning. The quality of life connected with health is lower than in the general population in the case of adults with Marfan syndrome, as was confirmed in studies (Fusar-Poli et al., 2008; Moon, Cho, Huh, Kang, \& Kim, 2016; Peters, Kong, Horne, Francomano, \& Biesecker, 2001; RandHendriksen et al., 2010; Ratiu, Virden, Baylow, Flint, \& Esfandiarei, 2018; Schoormans et al., 2012; Velvin, Bathen, Rand-Hendriksen, \& Geirdal, 2016) despite the fact that the abovementioned studies were carried out using the same tool and among them there are studies concerning the scale of lowering the quality of life which also indicate the lowering of overall indicators of quality of life and those which indicate particular areas in which the quality of life is lower in patients with Marfan syndrome in comparison with the general population.

There is an insufficient number of studies on the psychosocial aspects of functioning of children and adolescents with Marfan syndrome. So far, the studies have concentrated on the quality of life but their results are not consistent (Velvin, Wilhelmsen, Johansen, Bathen, \& Geirdal, 2019). On one hand, the results of the research of Handisides et al. (2019) $(n=321)$ indicate that children and adolescents have a lower quality of life than the general population, what is in accordance with a smaller study of Johansen et al. (2013) which included 10 parents of children with Marfan syndrome. Both studies were performed using the same tool. On the other hand, the results of the study of Mueller et al. (2016) indicate that adolescents with Marfan syndrome have the same quality of life or higher than the general population. Interestingly, the physical manifestations of phenotypical features were not associated with the level of quality of life of teenagers. The impact of
Chronically ill adolescents within the family system 
sex and age was not observed. In the study by Maryniak et al. (2011), the satisfaction of life in a group of adolescents between the age 11 and $18(n=29)$ was very diverse, averaging 7 sten. Interestingly, $25 \%$ of the studied adolescents expected a worsening of the satisfaction of life, which concerned the adolescents with more severe symptoms of the circulatory and skeletal systems.

Additionally, according to a study by Maryniak et al. (2011), 25\% of adolescents with Marfan syndrome aged 11-18 show internalizing symptoms in the form of depression, anxiety disorders, and tendencies to isolate themselves. The literature indicates that these are the only studies available which concerned the issues of internalizing and externalizing disorders in children and adolescents with Marfan syndrome.

Adolescents with JIA may experience symptoms of the diseases only for several months or throughout their lives. Due to pain and physical and motor limitations, adolescents experience stress during the disease (Seid, Huang, Niehaus, Brunner, \& Lovell, 2014). Moreover, they have the awareness of a deformed body/body image, and as a result of this, they experience anxiety concerning a lack of social acceptance (Reiter-Putrill, Gerhardt, Vannatta, Passo, \& Noll, 2003). They also feel anxious about the prognosis concerning the further course of the disease, treatment and the future in general. An additional source of stress for adolescents and their families is checkup visits and hospitalizations, which limit free time and the possibility to be in touch with peers. The reports show the difficulties with the adjustment of the adolescents with JIA and their families. Patients are sensitive or regress to the behaviors characteristic of younger children, they lose appetite and weight, and have various problems, especially internalizing ones (Beales, Holt, Keen, \& Mellor, 1983; Barlow, Shaw, \& Harrison, 1999). Adolescents have problems with sleeping which affects their behavioral and psychological functioning.

According to the studies of Ward et al. (2014), sleep problems are a predictor of externalizing disorders. Despite the abovementioned experimental difficulties connected with the specific nature of the disease, the studies concerning the psycho-social characteristics of children with JIA do not bring coherent results. There are studies which indicate that there are no differences between healthy adolescents and those with JIA (Rapoff, McGrath, \& Lindsey, 2003; Noll et al., 2000), which explains the different methodology of the study in relation to previous reports in which these differences were noticeable (Helgeson, Janicki, Lerner, \& Barbarin, 2003). Studies using the Child Behavior Checklist (CBCL) indicated no differences (Vandvik, 1990), whereas using the Child Assessment Schedule (CAS) psychiatric problems were diagnosed in $50 \%$ of patients (Hodges, McKnew, Burbach, \& Roebuck, 1987). Consistency is also lacking when comparing the studies in which only the CBCL tool was used (compare: Ward et al., 2014; Huygen, Kuis, \& Sinnema, 2000). In the studies in which these differences were revealed, adolescents with JIA had a higher level of depression, which was associated with pain (Margetić, Aukst-Margetić, Bilić, Jelušić, \& Bukovac, 2005). Similarly, a higher level of anxiety was associated with pain and low psychological inflexibility (Feinstein et al., 2011). Moreover, a meta-analysis which included mainly reports of the parents and only in two with adolescents showed that in a group with JIA there is a higher risk of internalizing behaviors, but not externalizing ones (LeBovidge, Lavigne, Donenberg, \& Miller, 2003). The difference indicating a higher level of internalization of difficulties was explained by among others physical limitations, e.g. actouts. In the recent studies using the CBCL (Memari, Chamanara, Ziaee, Kordi, \& Raeeskarami, 2016), there were higher results in JIA on the scales of problems - not only internalizing (fear/depression, withdrawal, somatic complaints) but also externalizing (behavioral disorders, aggressive disorders) and thought problems. The studied adolescents participating in the study were in the period of remission of symptoms and therefore they could experience fewer physical and motor limitations.

\section{THE FAMILY SYSTEM OF THE CHRONICALLY ILL CHILD}

Chronic illness is also a significant challenge for families who deal with the awareness of higher mortality, as in the case of Marfan syndrome, or increasing disability with time, as in the case of JIA. Fear for health of a family member or fear of their death contributes to the occurrence of symptoms of depression or signs of powerlessness (Ziarko, 2014).

Jakima and Małachowska (2000) draw attention to the complicated situation of family members of people suffering from Marfan syndrome. The most common psychological problems that parents of children with Marfan syndrome face are feelings of guilt (thinking of themselves as the person who caused this disease, intensified by the fact that it is genetically inherited), blaming the partner ("if you took better care of yourself, you wouldn't get sick"), fears about how the child will be perceived by their school mates (whether the unusual height and different appearance will cause the child to be picked on by their peers), anxiety about the future of the child (whether they will have a partner, or find a job), anxiety and fears associated with the risk of sudden complications and death of the child, and the fear that due to the rarity of this disease the child will not be treated appropriately by health professionals. On the other hand, family issues were addressed in the contact of satisfaction of life of parents of children 
with Marfan syndrome and the studies reveal that parents of children with Marfan syndrome assessed their satisfaction with life as medium or low; however, these results were significantly lower than the results of the general population. There were correlations between the satisfaction with life of the parents and social and school functioning of children with Marfan syndrome. The results of the studies of Peters, Kong, Horne, Francomano, and Biesecker (2001) showed that families of people with Marfan syndrome do not diverge from the results of the general population in the scope of the assessment of the functioning of the family and the level of general satisfaction with a marriage did not differ from the results of the general population. However, looking at particular scales, one can notice that the results obtained in the area of agreement, satisfaction and emotional expression by people with Marfan syndrome were significantly lower.There are few studies concerning the functioning of the family consisting of a teenager with JIA and the picture of the family system remains inconsistent when considering the perspective of various family members. In the studies where parents of children and adolescents were analyzed, it was found that parents of children with JIA perceived their families as more coherent and worse at adapting than the families of healthy children, and the parents of the adolescents did not differ. Adolescents with JIA perceived the families as less coherent in relation to adolescents without chronic diseases (Huygen et al., 2000 - a study with a Dutch version of FACES Olson). Moreover, better adaptation of children with JIA was noted if the cohesion of a family was higher (Huygen et al., 2000). The quality of life associated with the health of parents of the children with JIA was comparable to the parents of healthy children, which was explained by the fact the families were provided with therapy and good psycho-education (Holland). Worse results were obtained only on the scales of "social functioning" and "motor skills" (Haverman et al., 2014). In the studies concerning the quality of life of children with JIA, it was found that it is not associated with parental stress but its psychosocial functioning and problem behaviors present such a relation (Cavallo et al., 2009). The reports in which there are differences in the perception of problems in a teenager among family members indicate the need to study the whole family system. In Noll's studies (2000), mothers presented a difference in the scope of the internalizing symptoms between adolescents with JIA and adolescents without it; however, fathers and adolescents did not present such a difference.

A literature overview indicates that studies concerning internalizing and externalizing problems in adolescents with Marfan syndrome are very few and in the case of adolescents with JIA their results are inconsistent. Additionally, in the case of adolescents with JIA, the parents' reports are dominant. A metaanalysis of the team working under the supervision of LeBovidge (2003) indicates that only in 2 out of 21 studies concerning the internalizing and externalizing problems did the adolescents assess their functioning. There is a lack of studies concerning the functioning of the family system with teenagers with Marfan syndrome and with JIA, especially those which include the child's perspective.

Thus, the aim of the current study was: 1 ) to determine the differences in severity of internalizing and externalizing problems between young people with Marfan syndrome and adolescents with JIA, and adolescents without chronic disease; 2) to determine the differences between adolescents with Marfan syndrome and adolescents with JIA and young people without chronic disease in the perception of family functioning, and 3) to determine the relationship between the characteristics of the family system and externalizing and internalizing behaviors in adolescents with Marfan syndrome, adolescents with JIA and in a group of adolescents without chronic diseases. Related to the above objectives, the following research questions were formulated:

1. Are there any differences in terms of internalization and externalization disorders between chronically ill adolescents and adolescents without a chronic illness?

2. Are there any differences in the perception of the family system between chronically ill adolescents and adolescents without a chronic illness?

3. Is there a relationship between externalizing and internalizing disorders in adolescents who are chronically ill and their perception of the characteristics of their family system?

\section{PARTICIPANTS AND PROCEDURE}

\section{DESIGN AND PROCEDURE}

The described study is part of a larger project. The study was carried out as part of a research grant financed by SWPS University of Social Sciences and Humanities, Campus in Sopot (grant number: WSO/2016/A/04). As part of a larger research project on families, it received a positive opinion from the Research Projects Ethics Committee at the Psychology Institute of the University of Gdansk (request number 3/2016).

\section{PARTICIPANTS}

The cross-sectional study involved young people aged 11-18 (N=78): 1) with Marfan syndrome, staying in the Department of Pediatric Cardiology and Congenital Heart Defects of the Medical University of
Chronically ill adolescents within the family system 
Gdansk ( $n=25,48 \%$ girls and $52 \%$ boys), $11-18$ years of age $(M=13.96), 2)$ with JIA, under the care of the Jadwiga Titz-Kosko Provincial Rheumatology Clinic in Sopot ( $n=29,62 \%$ girls, 38\% boys), 11-17 years of age $(M=14.31)$ and 3$)$ adolescents without chronic illness ( $n=20,60 \%$ girls, $40 \%$ boys) $11-18$ years of age $(M=13.95)$.

Adolescents with Marfan syndrome participated in the multi-specialized support program for people with Marfan syndrome at the Medical University of Gdansk. Participation in the program was voluntary and possible by contacting the person responsible for its implementation. The psychological part of the research took place during the follow-up visit and concerned people who had already been diagnosed by specialists on the basis of the Ghent 2 criteria. The youth filled out a set of questionnaires in individual contact with a psychologist. During the follow-up visit, at least one parent of the adolescent was present, so it was possible to obtain consent to take part in the research from both the respondents and their legal guardians. The survey took place in the period from June 2016 to January 2018.

In the case of young people with JIA, the criterion for selection for the group was the diagnosis of the disease previously made by specialists. Questionnaire studies that took place in the period from July 2016 to May 2018 were carried out in individual contact with each patient during their stay in the clinic related to health control and/or rehabilitation. Before the survey, the respondent's parents were contacted to get permission to participate in the project.

\section{MEASUREMENT}

In order to carry out the research goals we used the adolescent version of the Child Behavior Checklist (Youth Self-Report; YSR; Polish adaptation by Wolańczyk, 2002) to assess the level of disorders and the Family Assessment Scale (Polish adaptation by Margasiński, 2015) to assess the family's characteristics in the perception of adolescents.

Youth Self-Report (YSR). The self-administered YSR scale includes the following problem sub-scale symptoms: Withdrawn (9 items, range: 0-18), Somatic Complaints (9 items, range: 0-18), Anxiety and Depression (14 items, range: 0-28), Social Problems (8 items, range: 0-16), Thought Problems (7 items, range: 0-14), Attention Problems (11 items, range: 0-22), Aggressive Behavior (20 items, range: 0-40) and Delinquent Behavior (13 items, range: 0-26). The participants respond to 112 items relating to various types of difficult behaviors on a scale from 0 to 2 , where 0 means that the statement is false, 1 means it is partially or sometimes true and 2 means it is completely or usually true. We calculate the result for each scale by adding points (0-1-2) to individual questions. The higher the score the greater the severity of behaviors that indicate a given set of symptoms. The total raw results for internalization and externalization scales are calculated by summing the raw scores of problem scales: Withdrawn, Somatic Complaints, Anxiety and Depression for Internalizing symptoms and Externalization Behavior and Aggressive Behaviors for Externalizing symptoms. YSR is a reliable and accurate tool often used in empirical studies in psychiatry and psychology to assess the level of occurrence of mental disorders in children and adolescents (Wolańczyk, 2002).

Family Assessment Scales. Family Assessment Scales (Polish adaptation of Olson's FACES-IV by Margasiński, 2015) were used to assess the functioning of the family system in the perception of adults and adolescent members of the family. The questionnaire consists of 62 statements to which the participants respond on a five-point scale from 1 (I totally disagree) to 5 (I totally agree) by assessing their level of satisfaction with the characteristics of the family system. The basic dimensions of the questionnaire are cohesion and flexibility of the family system. Indicators of family cohesion are the mutual emotional closeness of members of a given family, the quality of psychological boundaries between them, the degree of their openness, the amount and manner in which family members spend time together, the occurrence of family coalitions, the circle of friends, and to what extent the family decisions are consulted with everyone. There are three levels of cohesion: disengaged, connected and enmeshed. Indicators of flexibility in the family are: the scope of taking on the leadership role, the roles that individual members take, the rules which define the relationships of family members and the style of negotiations. There are three levels of flexibility: chaotic, flexible, rigid (Margasiński, 2015). The results are obtained for six subscales, two of which indicate the level of family balance (Cohesion, Flexibility) and four indicate the lack of balance in the family system (Disengaged, Enmeshed, Rigid, Chaotic). Each scale consists of 7 items, and the total sum of raw score ranges from 7 to 35 . In addition, it is possible to calculate scores for two evaluation scales (Family Communication - 10 items, range: 10-50 and Family Satisfaction - 10 items, range: 10-50). The subscales have a satisfactory internal validity and the confirmatory analysis showed that the Polish version of the tool has a structure consistent with Olson's Circumplex Model (Margasiński, 2015).

\section{DATA ANALYSIS}

In order to compare the adolescents with chronic illness and adolescents without chronic illness in terms of the severity of their problematic behaviors, because of the sizes of the groups we conducted the analyses using the non-parametric Kruskal-Wallis 
test, which examines the position of the traits in all groups that are being compared. The results of the Kruskal-Wallis test provide information on whether there are statistically significant differences between the compared groups, without the possibility to evaluate which groups are different from each other. To answer the question which groups differ significantly, we analyzed the data using Mann-Whitney test for the following group pairs: adolescents with Marfan syndrome and adolescents with JIA, adolescents with Marfan syndrome and adolescents without chronic illness, adolescents with JIA and adolescents without chronic illness. Data analysis was performed using SPSS version 25 and a $p$ value $<.05$ was considered statistically significant.

\section{RESULTS}

\section{DIFFERENCES IN TERMS OF INTERNALIZATION AND EXTERNALIZATION BEHAVIORS}

The table below (Table 1) shows the descriptive statistics concerning the severity of the problem behaviors in adolescents from the three studied groups, while the next table (Table 2) shows the comparison of the severity of these behaviors for each group.

Based on the obtained results, we can say that there are significant differences between the three groups on the scales of Social Problems, Attention Problems, Delinquent Behavior and overall for Externalizing behaviors.

Additional analyses for the group pairs allow us to state that in the area of Social Problems there are significant differences between the adolescents with JIA and adolescents without chronic illness $(Z=-2.46, p=.014)$ and the values of the mean ranges indicate that adolescents with JIA (mean range $=28.64$ ) experience them more often than the adolescents without chronic illness (mean range $=18.70$ ). In the case of Attention Problems we noted differences both between the adolescents with Marfan syndrome and adolescents with JIA $(Z=-1.98, p=.048)$, as well as between the adolescents with JIA and adolescents without chronic illness $(Z=-2.10, p=.036)$. Adolescents with JIA show more difficulties with concentration compared to both adolescents with Marfan syndrome (mean range $\mathrm{JIA}_{\mathrm{A}}=30.95$, mean range $\left._{\mathrm{MS}}=22.58\right)$ and adolescents without chronic illness (mean range $\mathrm{JIA}_{\mathrm{JA}}=28.07$, mean range $\mathrm{WCI}_{\mathrm{WC}}=19.50$ ). Delinquent Behaviors was found to be the variable dif-
Chronically ill adolescents within the family system

Table 1

Descriptive statistics of problem behavior in adolescents (raw results)

\begin{tabular}{|c|c|c|c|c|c|c|c|c|c|c|c|c|}
\hline \multirow[t]{2}{*}{ Scales } & \multicolumn{4}{|c|}{$\begin{array}{l}\text { Adolescents with MS } \\
\qquad(n=25)\end{array}$} & \multicolumn{4}{|c|}{$\begin{array}{l}\text { Adolescents with JIA } \\
\qquad(n=28)\end{array}$} & \multicolumn{4}{|c|}{$\begin{array}{l}\text { Adolescents WCI } \\
\quad(n=20)\end{array}$} \\
\hline & $M$ & $S D$ & $M e$ & Range & $M$ & $S D$ & $M e$ & Range & $M$ & $S D$ & $M e$ & Range \\
\hline Withdrawn & 5.20 & 2.89 & 5 & $1-11$ & 6.46 & 3.21 & 6.5 & $2-14$ & 4.65 & 3.05 & 5 & $1-13$ \\
\hline $\begin{array}{l}\text { Somatic } \\
\text { Complaints }\end{array}$ & 2.64 & 2.27 & 2 & $0-7$ & 3.89 & 3.19 & 3 & $0-13$ & 3.00 & 2.53 & 3 & $0-9$ \\
\hline $\begin{array}{l}\text { Anxiety and } \\
\text { Depression }\end{array}$ & 5.20 & 4.26 & 4 & $0-15$ & 7.69 & 6.39 & 6.5 & $0-25$ & 5.50 & 5.35 & 3.5 & $0-17$ \\
\hline $\begin{array}{l}\text { Social } \\
\text { Problems }\end{array}$ & 2.48 & 2.52 & 2 & $0-9$ & 3.42 & 2.69 & 3 & $0-12$ & 2.05 & 2.86 & 1 & $0-9$ \\
\hline $\begin{array}{l}\text { Thought } \\
\text { Problems }\end{array}$ & 1.96 & 1.49 & 2 & $0-7$ & 3.79 & 3.64 & 2 & $0-13$ & 2.15 & 2.21 & 1.5 & $0-8$ \\
\hline $\begin{array}{l}\text { Attention } \\
\text { Problems }\end{array}$ & 5.68 & 3.15 & 6 & $0-12$ & 7.79 & 4.19 & 8 & $0-20$ & 5.30 & 3.67 & 4 & $1-12$ \\
\hline $\begin{array}{l}\text { Delinquent } \\
\text { Behavior }\end{array}$ & 4.04 & 2.15 & 4 & $0-17$ & 6.25 & 3.95 & 5 & $0-21$ & 5.10 & 3.55 & 5 & $0-13$ \\
\hline $\begin{array}{l}\text { Aggressive } \\
\text { Behavior }\end{array}$ & 6.12 & 4.10 & 6 & $1-11$ & 9.68 & 6.49 & 8 & $1-34$ & 8.10 & 5.95 & 6.5 & $0-21$ \\
\hline $\begin{array}{l}\text { Internalizing } \\
\text { behaviors }\end{array}$ & 12.80 & 7.32 & 13 & $2-31$ & 16.60 & 9.32 & 14 & $3-36$ & 12.85 & 9.31 & 10.5 & $1-37$ \\
\hline $\begin{array}{l}\text { Externalizing } \\
\text { behaviors }\end{array}$ & 10.16 & 5.47 & 10 & $2-24$ & 15.93 & 10.03 & 13.5 & 3-55 & 13.20 & 9.13 & 10 & $2-34$ \\
\hline
\end{tabular}

Note. MS - Marfan syndrome, JIA - juvenile idiopathic arthritis, $\mathrm{WCI}$ - without chronic illness 
Table 2

Mean ranges for the problem behavior (raw results) and comparison of the participants in the studied groups (Kruskal-Wallis test)

\begin{tabular}{lcccccc}
\hline Measurement & $\begin{array}{c}\text { Adolescents } \\
\text { with MS } \\
(n=25)\end{array}$ & $\begin{array}{c}\text { Adolescents } \\
\text { with JIA } \\
(n=28)\end{array}$ & $\begin{array}{c}\text { Adolescents } \\
\text { WCI } \\
(n=20)\end{array}$ & $\chi^{2}$ & $d f$ & $p$ \\
\hline Withdrawn & 34.36 & 42.23 & 29.95 & 4.32 & 2 & .115 \\
Somatic Complaints & 33.18 & 41.25 & 35.83 & 2.04 & 2 & .362 \\
Anxiety and Depression & 33.50 & 40.65 & 33.08 & 2.11 & 2 & .349 \\
Social Problems & 35.32 & 44.27 & 28.93 & 6.51 & 2 & .039 \\
Thought Problems & 32.33 & 42.41 & 31.25 & 4.71 & 2 & .095 \\
Attention Problems & 33.76 & 44.52 & 30.53 & 6.01 & 2 & .049 \\
Delinquent Behavior & 29.78 & 44.20 & 35.95 & 6.29 & 2 & .043 \\
Aggressive Behavior & 30.48 & 43.05 & 36.68 & 4.67 & 2 & .097 \\
Internalizing behaviors & 33.36 & 41.06 & 31.23 & 3.03 & 2 & .220 \\
Externalizing behaviors & 30.00 & 44.18 & 35.70 & 6.02 & 2 & .049 \\
\hline
\end{tabular}

Note. MS - Marfan syndrome, JIA - juvenile idiopathic arthritis, $\mathrm{WCl}$-without chronic illness

ferentiating between adolescents with Marfan syndrome and adolescents with JIA $(Z=-2.65, p=.008)$. Adolescents from the first group experienced fewer difficulties than adolescents from the latter group (mean range $_{\mathrm{JA}}=32.25$, mean range MS $=21.12$ ). The overall score on the problematic Externalizing behaviors was significantly higher for the adolescents with JIA group compared to the group of adolescents with Marfan syndrome (mean range $_{\mathrm{JIA}}=32.25$, mean range $_{\mathrm{MS}}=21.12$; $Z=-2.62, p=.009)$.

\section{DIFFERENCES IN PERCEPTION OF THE FAMILY SYSTEM}

Table 3 presents the means and standard deviations for the eight scales which define the functioning of the family system and the two rating scales. Table 4 presents the results of the Kruskal-Wallis test, which was used to determine whether young people from the three compared groups differ in their assessment of family functioning.

Table 3

Descriptive statistics of the family system's characteristics - adolescents' perception (standardized results)

\begin{tabular}{|c|c|c|c|c|c|c|c|c|c|c|c|c|}
\hline \multirow[t]{2}{*}{ Scales } & \multicolumn{4}{|c|}{$\begin{array}{l}\text { Adolescents with MS } \\
\qquad(n=25)\end{array}$} & \multicolumn{4}{|c|}{$\begin{array}{l}\text { Adolescents with JIA } \\
\qquad(n=28)\end{array}$} & \multicolumn{4}{|c|}{$\begin{array}{l}\text { Adolescents WCI } \\
\quad(n=20)\end{array}$} \\
\hline & $M$ & $S D$ & Me & Range & $M$ & $S D$ & Me & Range & $M$ & $S D$ & $M e$ & Range \\
\hline Cohesion & 5.94 & 2.29 & 6 & $1-10$ & 4.43 & 1.87 & 4 & $1-9$ & 4.85 & 2.16 & 4.5 & $1-10$ \\
\hline Flexibility & 6.00 & 2.16 & 5.5 & $2-10$ & 4.61 & 1.87 & 4.5 & $2-9$ & 5.10 & 1.74 & 5 & $2-9$ \\
\hline Disengaged & 6.06 & 1.53 & 6.5 & $4-8$ & 7.52 & 1.99 & 8 & $4-10$ & 6.50 & 1.88 & 7 & $3-10$ \\
\hline Enmeshed & 5.69 & 1.49 & 6 & $3-7$ & 6.86 & 1.88 & 7 & $2-10$ & 6.20 & 1.99 & 6.5 & $2-10$ \\
\hline Rigid & 6.44 & 1.36 & 7 & $3-8$ & 6.26 & 1.32 & 7 & $4-10$ & 6.30 & 1.84 & 7 & $2-10$ \\
\hline Chaotic & 6.25 & 2.74 & 6,5 & $1-10$ & 7.96 & 1.86 & 8 & $3-10$ & 6.55 & 2.31 & 6.5 & $1-10$ \\
\hline $\begin{array}{l}\text { Family Com- } \\
\text { munication }\end{array}$ & 5.81 & 1.87 & 6 & $2-10$ & 5.10 & 2.34 & 4 & $1-10$ & 5.50 & 2.01 & 5 & $2-8$ \\
\hline $\begin{array}{l}\text { Family Satis- } \\
\text { faction }\end{array}$ & 7.31 & 1.96 & 7 & $4-10$ & 6.33 & 2.54 & 7 & $2-10$ & 6.40 & 2.06 & 7 & $2-10$ \\
\hline
\end{tabular}

Note. MS - Marfan syndrome, JIA - juvenile idiopathic arthritis, $\mathrm{WCl}$ - without chronic illness 
Table 4

Mean ranges concerning the characteristics of the family system (standardized results) and group comparison (Kruskal-Wallis test)

\begin{tabular}{lcccccc}
\hline Measure & $\begin{array}{c}\text { Adolescents } \\
\text { with MS } \\
(n=25)\end{array}$ & $\begin{array}{c}\text { Adolescents } \\
\text { with JIA } \\
(n=28)\end{array}$ & $\begin{array}{c}\text { Adolescents } \\
\text { WCI } \\
(n=20)\end{array}$ & $\chi^{2}$ & $d f$ & $p$ \\
\hline Cohesion & 41.53 & 27.93 & 31.68 & 5.68 & 2 & .058 \\
Flexibility & 40.63 & 27.68 & 32.75 & 5.12 & 2 & .077 \\
Disengaged & 25.13 & 39.62 & 29.70 & 7.12 & 2 & .029 \\
Enmeshed & 25.69 & 38.14 & 31.40 & 4.89 & 2 & .087 \\
Rigid & 34.72 & 30.37 & 32.03 & 0.63 & 2 & .728 \\
Chaotic & 26.84 & 39.61 & 27.08 & 7.51 & 2 & .023 \\
Family Communication & 37.41 & 29.98 & 33.85 & 1.69 & 2 & .431 \\
Family Satisfaction & 37.31 & 29.98 & 30.48 & 1.85 & 2 & .396 \\
\hline
\end{tabular}

Note. MS - Marfan syndrome, JIA - juvenile idiopathic arthritis, $\mathrm{WCI}$-without chronic illness

As can be concluded from the results presented above, adolescents with Marfan syndrome, adolescents with JIA and adolescents without chronic illness differ significantly in their perceptions of how Disengaged and Chaotic their families are. There were no significant differences for the scales of Cohesion, Flexibility and Enmeshed.

Additional analyses to compare results in pairs (between groups) revealed that adolescents with Marfan syndrome perceive their families as more cohesive

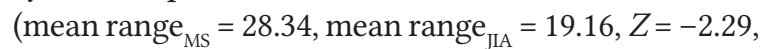
$p=.022$ ) and more flexible (mean range MS $=28.22$, mean range JIA $=19.23, Z=-2.24, p=.025$ ) than adolescents with idiopathic arthritis.

For Disengagement, there were statistically significant differences between the adolescents with Marfan syndrome and adolescents with JIA $(Z=-2.20$, $p=.028)$ and as a trend between adolescents with JIA and adolescents without chronic diseases $(Z=-1.71$, $p=.087)$. Mean ranges indicate that adolescents with JIA perceive their families as more disengaged compared to both the adolescents with Marfan syndrome (mean range $_{\mathrm{JIA}}=26.19$, mean range $\mathrm{MS}_{\mathrm{MS}}=17.22$ ) and adolescents without chronic illness (mean range ${ }_{\mathrm{JIA}}=27.90$, mean range $\left._{\mathrm{WCI}}=20.80\right)$. We also found a statistically significant difference for the Enmeshed scale between adolescents with Marfan syndrome (mean range $_{\mathrm{MS}}=16.53$ ) and adolescents with JIA (mean range $\left._{\mathrm{JIA}}=26.57\right)(Z=-2.47, p=.014)$, whereby the values of the mean ranges indicate that people from the second group perceive their families as having a higher level of family imbalance manifested by excessive entanglement of family members in mutual relations. The results on the Chaotic scale differentiated significantly between the groups, and the results of the paired analyses we conducted revealed that ad- olescents with JIA scored higher on that scale compared to adolescents with Marfan syndrome (mean range $_{\mathrm{JIA}}=25.66$, mean range ${ }_{\mathrm{MS}}=16.97, Z=-2.17$, $p=.030)$ as well as compared to adolescents without chronic diseases (mean range JIA $=28.25$, mean range $\left._{\mathrm{WCI}}=19.25, Z=-2.20, p=.028\right)$.

\section{RELATIONSHIP BETWEEN EXTERNALIZING AND INTERNALIZING BEHAVIORS IN ADOLESCENTS AND THEIR PERCEPTION OF THE CHARACTERISTICS OF THEIR FAMILY SYSTEM}

In order to understand better the relationship between externalizing and internalizing behaviors in adolescents suffering from chronic illnesses and the features of the family system perceived by them, we carried out correlation analyses using the Spearman test.

Among the adolescents with Marfan syndrome, the relationship between the family system's features and the delinquent behaviors was revealed. The higher the level of Disengagement of family members $(r=.48, p=.061)$, the worse the Family Communication $(r=-.49, p=.056)$ and Family Satisfaction $(r=-.53, p=.036)$, the more difficulties with socialization among the studied adolescents. In addition, there was a relationship between the score on the Somatic Complaints scale and Chaotic scale - in the perception of the adolescents, the fewer rules were in force in their family, the more somatic complaints were reported by the ill adolescents $(r=.50, p=.050)$.

The functioning of a family with a child with JIA is mainly related to the externalizing disorders of the suffering adolescent. The less cohesive the fam-
Chronically ill adolescents within the family system 
Agnieszka

Trawicka,

Aleksandra

Lewandowska-

Walter,

Marta

Bogdanowicz,

Lidia Woźniak-

Mielczarek,

Dorota

Janikowska-

Hołoweńko,

Magdalena

Bilicka-Siewert ily $(r=-.38, p=.050)$ and the less satisfaction with family life $(r=-.40, p=.045)$, and at the level of statistical tendency, also the lower the level of Flexibility $(r=-.34, p=.085)$ and Enmeshed $(r=-.34, p=074)$ and worse Family Communication $(r=-.36, p=.061$ ), the more Delinquent Behaviors of young people with JIA. The weaker the family bond (Cohesion: $r=-.41$, $p=.036$; Disengaged: $r=.38, p=.045)$ the less satisfactory, in the assessment of the adolescents, Family Communication $(r=-.46, p=.014)$ and overall family life $(r=-.41, p=.038)$, the more aggressive behaviors are manifested by adolescents with idiopathic arthritis. Externalizing behaviors overall are related to the family member ties $(r=-.42, p=.031)$, communication $(r=-.45, p=.017)$ and satisfaction with family life $(r=-.44, p=.024)$. The worse the family's functioning in these areas, the larger the number of problems which are revealed outside by adolescents with idiopathic arthritis.

We found a different pattern of results concerning the relationship between family system characteristics and adolescents' problems among the adolescents without chronic disease, compared to the adolescents with Marfan syndrome and JIA. A feature of the system's functioning that was the most significant for the emergence of problem behaviors in adolescents was the score on the Disengagement and Chaotic scales. The weaker the ties in the family and the fewer the rules in force, in the perception of adolescents, the more internalization disorders (Disengaged: $r=.56, p=.010$, Chaotic: $r=.46, p=.042)$, primarily in the form of Withdrawal $(r=.72, p<.001)$. In addition, we did not observe a significant relationship of the discussed family trait with Anxiety and Depression $(r=.40, p=.078)$, Social Problems $(r=.44$, $p=.055)$, Attention Problems $(r=.44, p=.055)$ or Delinquent Behaviors $(r=.39, p=.093)$; therefore we should be careful when interpreting those results.

\section{DISCUSSION}

Our results indicated that adolescents with Marfan syndrome have similar scores compared to adolescents without illness on all subscales concerning both internalizing and externalizing behaviors, as well as the family system's characteristics. Compared to adolescents with JIA, adolescents with Marfan syndrome had lower scores on externalization symptoms and attention problems. A family system is perceived as a better functioning by adolescents with Marfan syndrome than by adolescents with JIA - on the scales indicating the balance of a family system, adolescents with Marfan syndrome achieved higher results; however, on 3 out of 4 scales indicating a lack of balance in the family, adolescents with JIA got lower results. Our results indicate that adolescents with Marfan syndrome do not differ from adolescents free from a chronic illness with internalizing and externalizing problems. This does not mean that adolescents with this illness do not have, for example, symptoms of depression or anxiety. As reported by Maryniak et al. (2011), 25\% of adolescents with Marfan syndrome suffer from depression. In a quoted study in which the CBCL was also applied, the results obtained by adolescents with Marfan syndrome referred to norms. In the studies conducted in Poland one can infer that depression occurs in $20 \%$ and even $65 \%$ of adolescents, and $25 \%$ of them require treatment (Dymowska \& Nowicka-Sauer, 2015; Modrzejewska \& Bomba, 2010). It is emphasized that depression in adolescence may be treated as a specific reaction associated with the development but also as a nosologic unit, and this differentiation conditions the therapy (Iniewicz, 2008). With regards to the results obtained by us, the statistics explain why adolescents with Marfan syndrome experience internalizing symptoms to a similar extent as their healthy peers. A literature overview suggests that our study is the first study in which adolescents with Marfan syndrome were compared with adolescents without a chronic illness. It confirms that depression and anxiety constitute problems occurring at this stage of development, regardless of health problems. However, the result may still surprise due to the fact that we are dealing with a life-threatening disease.

Another explanation for the lack of differences between adolescents with Marfan syndrome and adolescents without illness regarding internalization and externalization problems concerns the defense mechanisms activated by children and adolescents in the face of chronic illness (see Obuchowska, 2003). These include suppressing fear or minimizing this feeling, as indicated, in the case of children and young people with Marfan syndrome, by, among others, Maryniak et al. (2011). Difficulties in sharing one's feelings, including blocking out anxiety and withdrawal of children with severe cardiological issues, were shown in studies by Giuffre and colleagues (2008). Their studies involved children with long QT syndrome (LQT), which, as in the case of Marfan syndrome, is associated with sudden death if there is no adequate diagnosis. The authors explain lower than expected levels of internalization behaviors, including in comparison to children with asthma, with the lack of physical experiences among the children with LQT and the need for social acceptance and the tendency to satisfy the needs of other people. A similar explanation seems to be well founded in the case of young people with Marfan syndrome, who do not feel any discomfort day to day, and due to the differences in appearance may look for the acceptance of peers and significant people to a larger extent than usual in adolescence. Additionally, both the adolescents as well as parents of children with rare diseases indicate the difficulty in sharing their fears related to symptoms and prog- 
nosis, when they do not feel that others will understand their problems due to the lack of knowledge about the disease (see Müller-Godeffroy, Lehmann, Küster, \& Thyen, 2005).

Lack of differences in the scope of perception of functioning of a family system by adolescents with Marfan syndrome and adolescents without a chronic illness may suggest that both patients and their parents develop mechanisms allowing them to deal with anxiety. Thanks to this, the quality of life is compared to the general population both on an individual level - according to Mueller et al. (2016) adolescents with Marfan syndrome have the same or even higher quality of life than the general population - as well as at the family level - Peters et al. (2001) indicated that families of people with Marfan syndrome do not deviate from the results of the general population in the field of the assessment of the functioning of the family.

The results we obtained indicated the existence of statistically significant differences between the adolescents with Marfan syndrome and adolescents with JIA. Both for the overall results and on the scales of Social Problems, Delinquent Behavior and Attention Problems the adolescents with idiopathic arthritis showed more problematic behaviors than adolescents with Marfan syndrome. Juvenile idiopathic arthritis is a disease closely related to pain symptoms, which, according to a study by Margetić et al. (2005) and Feinstein et al. (2011) are associated with behavioral problems. Rebellion, manifested through behaviors oppositional to the disease and treatment, can be expressed by impulsive or aggressive behavior, that is, externalization of difficulties and tensions which the child experiences. Also the motivation to undertake intellectual effort also disappears, causing difficulties in concentrating on learning, when the pain is troublesome and chronic (see Pilecka, 2011), which may explain more attention problems in the group of adolescents with JIA compared to adolescents with Marfan syndrome. The study of Ward et al. (2014) suggests that adolescents with JIA experience problems with sleep, which may differentiate them from adolescents with Marfan syndrome. The reason for sleep disturbance is pain and its consequence - externalizing behavior problems (Ward et al., 2014).

The obtained results of our research also indicate different perception of the characteristics of the family system by young people with Marfan syndrome and with JIA. We found differences which indicate a better functioning of the family system in the perception of adolescents with Marfan syndrome compared to adolescents with idiopathic arthritis, in terms of both family cohesion and flexibility. The adolescents with idiopathic arthritis obtained lower scores on the $\mathrm{Co}^{-}$ hesion and Flexibility scale and higher scores on the Disengaged, Enmeshed and Chaotic scales. In comparison with adolescents with Marfan syndrome, young patients with idiopathic arthritis view their family as less balanced, which means worse functioning of the whole system as well as individual members of the family. As noted in the literature, a child's disease can have a varied impact on the family system in terms of the proximity of its members and the ability to react in difficult situations (see Zubrzycka, 2014). What differentiates the two diseases discussed in this paper is the intensity of chronic pain, which is stronger in people with idiopathic arthritis, and the constant threat of death always present for the people with Marfan syndrome. These differences are related to different tasks for family members as child carers - in the case of Marfan syndrome, the ill person requires control and observation, but on a daily basis the doctor's recommendation is "to try to live normally", and to reduce stress and excessive physical activity (Woźniak-Mielczarek, 2017). Therefore, a family raising a teenager with Marfan's syndrome can show special efforts to provide a favorable, stressfree emotional atmosphere. Anxiety is undoubtedly experienced by every member of the family, but its expression can be inhibited, so as not to "infect" the loved one with it and, at the same time, so that it does not spread throughout the family system (see Namysłowska \& Siewierska, 2001). This mechanism, although not providing long term benefits for mental health, in the case of a chronic disease in the family can be used to maintain homeostasis. Families of adolescents with JIA experience more child's pain and complaints on a daily basis (Seid et al., 2014; ReiterPutrill et al., 2003), which may be the source of family conflicts. The way of responding to the pain influences the child's attitude towards the situation of disease and affects the meaning the child attributes to their pain experience. Parents can encourage the child to undertake different activities despite the pain, or be overly focused on the child's pain and exacerbate their mental discomfort. Undeniably, each type of pain is a source of distress for the whole family. Parent's behaviors influence the child's behavior when experiencing pain, through their strategies to deal with the problem and the meaning they assign to the child's illness (Cavallo et al., 2009). Children with recurrent pain are often unable to deal with anxiety flexibly and sooth their own pain (see Pilecka, 2011). However, when assessing the current functioning of the family, it is worth considering the condition before the child's illness, because the disease can make the families that are coherent and easily adaptable to challenges stronger; while in the case of families who are in conflict and experience difficulties even before the illness, loss of health can lead to a serious crisis in relationships, including the breakdown of the system (Szabała, 2009).

The results concerning the relationship between the functioning of the family system and the intensity of internalizing and externalizing disorders show
Chronically ill adolescents within the family system 
an interdependent relationship of family characteristics with externalizing behavior in adolescents with Marfan syndrome and with JIA. In the case of adolescents without chronic disease, the features of the system correlated with the internalizing behaviors. In both groups - adolescents who are chronically ill and adolescents without a chronic illness - the results of our research can be understood in the context of the systemic functioning of the family, that is, responding with problems and difficulties in functioning by the adolescent when the relations in the family are not developing correctly (see Minuchin et al., 1975, Rolland, 1987, 1999). During the "family with adolescent" phase, the cohesion of the family as a system diminishes, which is correct and results from developmental tasks carried out by the child, which are expressed, among others, through emotional separation, which is necessary to shape individual identity. Adolescents who are not chronically ill react primarily through withdrawal from social relations in response to weaker family relationships and lack of clear rules in the family. To a lesser extent, they express the experienced difficulties and fears linked to what is happening in the family, which can be interpreted as an extension of the developmental pattern of separation (Carter \& McGoldrick, 1989). In the perception of young people with JIA and Marfan syndrome the weaker the family bond is, the stronger is the intensity of externalizing behaviors. The obtained results correspond with previous ones concerning children with JIA - the better the family coherence, the better their adjustment (Huygen et al., 2000). In the case of adolescents with Marfan syndrome, so far no study concerning the perception of functioning of the family system has been conducted. However, we may assume that adolescents with Marfan syndrome may need more support from parents and therefore they perceive their overprotection positively. "Close families with structured roles" (Huygen et al., 2000, p. 281) - such a structure of the family system may be more functional in the perception of adolescents suffering from both types of chronic illnesses.

It can be more difficult for parents of chronically ill children, compared to parents of children without chronic illness, to correctly respond to developmental changes, due to their own anxiety related to their child's health (JIA) or child's life (Marfan syndrome) and the sense of helplessness they experience. Parents' negative emotional states linked to the child's illness influence the family climate and can exacerbate the symptoms (Marfan syndrome) and the experienced pain (JIA), which will be expressed by the adolescents in order to convince their parents to restore their caring behaviors and provide constant support (see Pilecka, 2011), and thus maintaining the balance in the system. Externalizing behaviors usually cause a faster reaction of the environment than internalization, and thus can act to unify the family around the child's difficulties related directly to the disease or its consequences manifesting in school or in relationships with peers.

\section{LIMITATIONS AND FURTHER RESEARCH}

Undoubtedly, the research limitations include its correlational character, which does not allow us to determine the direction of the mutual influence of the functioning of the child and the family. Due to the cross-sectional type of the study, it was not possible to determine the impact of time on changes in the severity of internalization and externalization problems. The research included a small trial that could not reveal all relations between variables. Therefore, the possibilities to generalize the obtained results are limited. They may not reflect the functioning of a wider youth population with Marfan syndrome and JIA, also due to the fact that people under the care of two centers were examined. In the future, it would be worth taking into account the patients of other hospitals and health centers. The specificity of the group of young people with Marfan syndrome also results from the arbitrary participation in the project, in which patients were included in the diagnosis, care and medical supervision. Therefore, parents who are looking for information about the disease, concerned and particularly caring about the child's health, were able to apply for participation in the project. Often the parents themselves were burdened with the disease, which would be worth observing in the future. Marfan syndrome may manifest itself through inheritance or be de novo, so in further research it is worth considering this aspect as differentiating the group of patients. There may be a difference between the functioning of families where a specific health problem has already been present, where death of a close relative has been experienced, in contrast to a family where the Marfan syndrome occurred for the first time. Due to reports suggesting different perceptions by individual family members of the severity of problems in the behavior of a teenager, the next project could include parent-teenager dyads or mother-father-adolescent triads.

\section{IMPLICATIONS FOR CLINICAL PRACTICE AND FURTHER RESEARCH}

Taking into consideration the obtained results of studies in the field of internalizing and externalizing in adolescents JIA, it is worth including the screening towards the diagnosis of depression in clinical practice. Depression in adolescents assumes a different clinical image than in adults. Moreover, the results of the study suggest that depression is connected with the aggravation of a somatic condition. It is worth 
considering the introduction of activities which may define the level of awareness of the disease and its influence on the life and psycho-education in the scope of recognition of emotions into clinical practice in adolescents with Marfan syndrome. Lack of acceptance of the disease makes it impossible to undergo the process of adaptation of disease and dealing with it. The hypothesis that patients with Marfan syndrome remain in the condition of disconnection from their emotions and state of being seems worth considering in the context of the results of the study showing lack of differences in the scope of somatic complaints between healthy people and adolescents with Marfan syndrome.

Despite the limitations of the present report, the obtained results show that it is worthwhile to analyze more thoroughly and from a wider perspective both individual functioning and the family system of young people with Marfan syndrome and JIA. The results concerning adolescents with Marfan syndrome are especially valuable, due to the small number of studies carried out thus far, making it now possible to ask further research questions and create new hypotheses related to this group. On the one hand, we should explore the defense mechanisms and the tendency of the adolescents with chronic disease to present themselves in a better light, and on the other hand, the effect of post-traumatic personal growth should be taken into account. The results indicating an increase in externalizing behaviors in the case of young people with JIA, compared to adolescents with Marfan syndrome and the healthy population, are also interesting, because previous research has tended to focus on internalization behaviors in this group of patients. It seems that further studies should look into family relations and their connections to the functioning of adolescents with Marfan syndrome and JIA. The aim of such studies would be to explain the mechanism of externalizing among adolescents with both JIA and Marfan's syndrome as the result of irregularities in the functioning of the family system.

\section{CONCLUSIONS}

The literature review shows that our study is the first in which the internalization and externalizing behaviors of adolescents with Marfan syndrome were compared with those of a group of adolescents not burdened with chronic disease. The results of our study suggest that adolescents with Marfan syndrome function on a daily basis similarly to peers who are not burdened with chronic disease, which may be related to the lack of noticeable daily complaints. It is different in the case of adolescents with JIA, who in relation to adolescents with Marfan syndrome and healthy youth present more intensified problems of externalization, related to, inter alia, pain. The results of previous studies on internalizing and externalizing behaviors presented by adolescents with JIA are not consistent. Our results partially confirm the results of the Memari et al. (2016) study, in which, similarly to our study, JIA adolescents show higher rates of Aggressive Behaviors and Social Problems than the control group.

In the case of adolescents with Marfan syndrome, also no studies have yet been conducted regarding their perception of the functioning of the family system. The findings indicate that adolescents with Marfan syndrome perceive their families as more balanced than adolescents with JIA. Cohesive structure of the family system may be more functional in the perception of adolescents suffering from both Marfan syndrome and JIA. Strong family ties are associated with a lesser severity of externalizing behaviors. In the case of Marfan syndrome, we need further research. In the case of JIA, the obtained results correspond with earlier ones - the higher the cohesion of the family, the better adaptation of adolescents with JIA (Huygen et al., 2000).

\section{References}

Adams, J. N., \& Trent, R. J. (1998). Aortic complications of Marfan's syndrome. The Lancet, 352, 1722-1723. https://doi.org/10.1016/S0140-6736(05)79822-6

Barlow, J. H., Shaw, K. L., \& Harrison, K. (1999). Consulting the 'experts': children's and parents' perceptions of psycho-educational interventions in the context of juvenile chronic arthritis. Health Education Research, 14, 597-610. https://doi.org/10.1093/ her/14.5.597

Beales, J. G., Holt, P. J., Keen, J. H., \& Mellor, V. P. (1983). Children with juvenile chronic arthritis: their beliefs about their illness and therapy. Annals of the Rheumatic Diseases, 42, 481-486. https://doi.org/10.1136/ard.42.5.481

Bolanowski, J., \& Wrzosek, Z. (2007). Choroby reumatyczne: podręcznik dla studentów fizjoterapii [Rheumatic diseases: a textbook for physiotherapy students]. Wrocław: Wydawnictwo Akademii Wychowania Fizycznego we Wrocławiu.

Carter, B., \& McGoldrick, M. (Eds.) (1989). The changing family life cycle: A framework for family therapy. Needham Heights, MA: Allyn and Bacon.

Cavallo, S., Feldman, D. E., Swaine, B., Meshefedjian, G., Malleson, P. N., \& Duffy, C. M. (2009). Is parental coping associated with quality of life in juvenile idiopathic arthritis? Pediatric Rheumatology, 7, 7. https:// doi.org/10.1186/1546-0096-7-7

Dean, J. C. (2007). Marfan syndrome: clinical diagnosis and management. European Journal of $\mathrm{Hu}$ man Genetics, 15, 724-733. https://doi.org/10.1038/ sj.ejhg.5201851
Chronically ill adolescents within the family system 
Dietz, H. C., Cutting, C. R., Pyeritz, R. E., Maslen, C. L., Sakai, L. Y., Corson, G. M., Puffenberger, E. G., Hamosh, A., Nanthakumar, E., Curristin, S. M., Stetten, G., Meyers, D. A., \& Francomano, C. A. (1991). Marfan syndrome caused by a recurrent de novo missense mutation in the fibrillin gene. $\mathrm{Na}$ ture, 352, 337-339. https://doi.org/10.1038/352337a0

Dymowska, A., \& Nowicka-Sauer, K. (2015). Depresja wśród młodzieży - problem wciąż aktualny [Depression among adolescents - the problem is still valid]. Forum Medycyny Rodzinnej, 9, 124-126.

Agnieszka

Trawicka,

Aleksandra

Lewandowska-

Walter,

Marta

Bogdanowicz,

Lidia Woźniak-

Mielczarek,

Dorota

Janikowska-

Hołoweńko,

Magdalena

Bilicka-Siewert

Erkula, G., Jones, K. B., Sponseller, P. D., Dietz, H. C., \& Pyeritz, R. E. (2002). Growth and maturation in Marfan syndrome. American Journal of Medical Genetics, 109, 100-115. https://doi.org/10.1002/ ajmg.10312

Feinstein, A. B., Forman, E. M., Masuda, A., Cohen, L. L., Herbert, J. D., Moorthy, L. N., \& Goldsmith, D. P. (2011). Pain intensity, psychological inflexibility, and acceptance of pain as predictors of functioning in adolescents with juvenile idiopathic arthritis: a preliminary investigation. Journal of Clinical Psychology in Medical Settings, 18, 291-298. https://doi. org/10.1007/s10880-011-9243-6

Fusar-Poli, P., Klersy, C., Stramesi, F., Callegari, A., Arbustini, E., \& Politi, P. (2008). Determinants of quality of life in Marfan syndrome. Psychosomatics, 49, 243-248. https://doi.org/10.1176/appi. psy.49.3.243

Giuffre, R. M., Gupta, S., Crawford, S. G., \& Leung, A. K. (2008). Fears and anxiety in children with long-QT syndrome compared to children with asthma. Journal of the National Medical Association, 100, 420424. https://doi.org/10.1016/s0027-9684(15)31275-x

Glard, Y., Launay, F., Edgard-Rosa, G., Collignon, P., Jouve, J. L., \& Bollini, G. (2008). Scoliotic curve patterns in patients with Marfan syndrome. Journal of Children's Orthopaedics, 2, 211-216. https:// doi.org/10.1007/s11832-008-0095-z

Handisides, J. C., Hollenbeck-Pringle, D., Uzark, K., Trachtenberg, F. L., Pemberton, V. L., Atz, T. W., Bradley, T. J., Cappella, E., De Nobele, S., Groh, G. K., Hamstra, M. S., Korsin, R., Levine, J. C., Lindauer, B., Liou, A., Neal, M. K. M., Markham, L. W., Morrison, T., Mussatto, K. A., Olson, A. K., Pierpont, M. E. M., Pyeritz, R. E., Radojewski, E. A., Roman, M. J., Xu, M., \& Lacro, R. V. (2019). Health-related quality of life in children and young adults with Marfan syndrome. The Journal of Pediatrics, 204, 250-255. https://doi. org/10.1016/j.jpeds.2018.08.061

Haverman, L., van Oers, H. A., Maurice-Stam, H., Kuijpers, T. W., Grootenhuis, M. A., \& van Rossum, M. A. (2014). Health related quality of life and parental perceptions of child vulnerability among parents of a child with juvenile idiopathic arthritis: results from a web-based survey. Pediatric Rheumatology, 12, 34. https://doi.org/10.1186/15460096-12-34
Helgeson, V. S., Janicki, D., Lerner, J., \& Barbarin, O. (2003). Brief report: Adjustment to juvenile rheumatoid arthritis: A family systems perspective. Journal of Pediatric Psychology, 28, 347-353. https:// doi.org/10.1093/jpepsy/jsg024

Heszen, I. (2005). Zmienność wymiarów zdrowia na przestrzeni życia człowieka [Variability of health dimensions throughout human life]. In D. KubackaJasiecka \& T. M. Ostrowski (Eds.), Psychologiczny wymiar zdrowia, kryzysu i choroby [Psychological dimension of health, crisis and disease] (pp. 2136). Kraków: Wydawnictwo Uniwersytetu Jagiellońskiego.

Heszen, I., \& Sęk, H. (2007). Psychologia zdrowia [Health psychology]. Warszawa: Wydawnictwo Naukowe PWN.

Hodges, K., McKnew, D. O. N., Burbach, D. J., \& Roebuck, L. (1987). Diagnostic concordance between the Child Assessment Schedule (CAS) and the Schedule for Affective Disorders and Schizophrenia for SchoolAge Children (K-SADS) in an outpatient sample using lay interviewers. Journal of the American Academy of Child and Adolescent Psychiatry, 26, 654-661. https://doi.org/10.1097/00004583-198709000-00008

Huygen, A. C. J., Kuis, W., \& Sinnema, G. (2000). Psychological, behavioural, and social adjustment in children and adolescents with juvenile chronic arthritis. Annals of the Rheumatic Diseases, 59, 276-282. https://doi.org/10.1136/ard.59.4.276

Iniewicz, G. (2008). The specific features of adolescent depression - from developmental reaction to clinical syndrome. Polish Psychological Bulletin, 39, 154-157. https://doi.org/10.2478/v10059-008-0019-2

Jakima, S., \& Małachowska, E. (2000). Problemy psychologiczne w zespole Marfana [Psychological problems in Marfan syndrome]. In B. Rudzińska (Ed.), Zespót Marfana. Charakterystyka schorzenia i studia przypadków osób nim dotkniętych [Marfan syndrome. Characteristics of the disease and case studies of people affected] (pp. 158-171). Warszawa: Wydawnictwa Tyflologiczne PZN.

Johansen, H., Dammann, B., Andresen, I. L., \& Fagerland, M. W. (2013). Health-related quality of life for children with rare diagnoses, their parents' satisfaction with life and the association between the two. Health and Quality of Life Outcomes, 11, 152. https://doi.org/10.1186/1477-7525-11-152

Jondeau, G., Detaint, D., Tubach, F., Arnoult, F., Milleron, O., Raoux, F., Delorme, G., Mimoun, L., Krapf, L., Hamroun, D., Beroud, C., Roy, C., Vahanian, A., \& Boileau, C. (2012). Aortic event rate in the Marfan population: a cohort study. Circulation, 125, 226232. https://doi.org/10.1161/CIRCULATIONAHA. 111.054676

Keane, M. G., \& Pyeritz, R. E. (2008). Medical management of Marfan syndrome. Circulation, 117, 28022813. https://doi.org/10.1161/CIRCULATIONAHA. 107.693523 
LeBovidge, J. S., Lavigne, J. V., Donenberg, G. R., \& Miller, M. L. (2003). Psychological adjustment of children and adolescents with chronic arthritis: a metaanalytic review. Journal of Pediatric Psychology, 28, 29-39. https://doi.org/10.1093/jpepsy/28.1.29

Marcelli, D. (2013). Psychopatologia wieku dziecięcego [Psychopathology of childhood]. Wrocław: Edra Urban \& Partner.

Margasiński, A. (2015). The Polish Adaptation of FACES IV-SOR. Polish Journal of Applied Psychology, 13, 4366. https://doi.org/10.1515/pjap-2015-0025

Margetić, B., Aukst-Margetić, B., Bilić, E., Jelušić, M., \& Bukovac, L. T. (2005). Depression, anxiety and pain in children with juvenile idiopathic arthritis (JIA). European Psychiatry, 20, 274-276. https://doi. org/10.1016/j.eurpsy.2004.12.014

Maryniak, A., Bielawska, A., Gorbacz-Mrowiec, Ł., \& Kawalec, W. (2011). Objawy psychopatologiczne i satysfakcja z życia młodzieży z zespołem Marfana [Psychopathological symptoms and satisfaction with the life of young people with Marfan syndrome]. Psychologia Jakości Życia, 2, 131-142.

Maumenee, I. H. (1981). The eye in the Marfan syndrome. Transactions of the American Ophthalmological Society, 79, 684-733.

Memari, A. H., Chamanara, E., Ziaee, V., Kordi, R., \& Raeeskarami, S. R. (2016). Behavioral problems in juvenile idiopathic arthritis: a controlled study to examine the risk of psychopathology in a chronic pediatric disorder. International Journal of Chronic Diseases, article ID 5726236. https://doi. org/10.1155/2016/5726236

Minuchin, S., Baker, L., Rosman, B. L., Liebman, R., Milman, L., \& Todd, T. C. (1975). A conceptual model of psychosomatic illness in children: Family organization and family therapy. Archives of General Psychiatry, 32, 1031-1038. https://doi.org/10.1001/ archpsyc. 1975.01760260095008

Modrzejewska, R., \& Bomba, J. (2010). A comparative study of adolescent depression among high school pupils in a large Polish city. Archives of Psychiatry and Psychotherapy, 12, 19-22.

Moon, J. R., Cho, Y. A., Huh, J., Kang, I. S., \& Kim, D. K. (2016). Structural equation modeling of the quality of life for patients with Marfan syndrome. Health and Quality of Life Outcomes, 14, 83. https:// doi.org/10.1186/s12955-016-0488-5

Mueller, G. C., Steiner, K., Wild, J. M., Stark, V., Kozlik-Feldmann, R., \& Mir, T. S. (2016). Healthrelated quality of life is unimpaired in children and adolescents with Marfan syndrome despite its distinctive phenotype. Acta Paediatrica, 105, 311-316. https://doi.org/10.1111/apa.13264

Müller-Godeffroy, E., Lehmann, H., Küster, R. M., \& Thyen, U. (2005). Quality of life and psychosocial adaptation in children and adolescents with juvenile idiopathic arthritis and reactive arthritis.
Zeitschrift fur Rheumatologie, 64, 177-187. https:// doi.org/10.1007/s00393-005-0652-5

Namysłowska, I., \& Siewierska, A. (2001). Lęk w systemie rodzinnym [Anxiety in the family system]. Psychiatria Polska, 28, 547-557.

Nemet, A. Y., Assia, E. I., Apple, D. J., \& Barequet, I. S. (2006). Current concepts of ocular manifestations in Marfan syndrome. Survey of Ophthalmology, 51, 561-575. https://doi.org/10.1016/j.survophthal. 2006.08.008

Noll, R. B., Kozlowski, K., Gerhardt, C., Vannatta, K., Taylor, J., \& Passo, M. (2000). Social, emotional, and behavioral functioning of children with juvenile rheumatoid arthritis. Arthritis \& Rheumatism, 43, 1387-1396. https://doi.org/10.1002/15290131(200006)43:6<1387::AID-ANR24>3.0.CO;2-C

Obuchowska, I. (2003). Kochać i rozumieć. Część 3 [Love and understand. Part 3]. Poznań: Media Rodzina.

Peters, K. F., Kong, F., Horne, R., Francomano, C. A., \& Biesecker, B. B. (2001). Living with Marfan syndrome I. Perceptions of the condition. Clinical Genetics, 60, 273-282. https://doi.org/10.1034/j.13990004.2001.600405.x

Pilecka, W. (2011). Psychologia zdrowia dzieci i mtodzieży. Perspektywa kliniczna [Psychology of health of children and adolescents. Clinical perspective]. Kraków: Wydawnictwo Uniwersytetu Jagiellońskiego.

Rand-Hendriksen, S., Johansen, H., Semb, S. O., Geiran, O., Stanghelle, J. K., \& Finset, A. (2010). Healthrelated quality of life in Marfan syndrome: a crosssectional study of Short Form 36 in 84 adults with a verified diagnosis. Genetics in Medicine, 12, 517524. https://doi.org/10.1097/GIM.0b013e3181ea4c1c Rapoff, M. A., McGrath, A. M., \& Lindsey, C. B. (2003). Medical and psychosocial aspects of juvenile rheumatoid arthritis. In M. C. Roberts (Ed.), Handbook of Pediatric Psychology: Third Edition (pp. 392-408). New York: Guilford.

Ratiu, I., Virden, T. B., Baylow, H., Flint, M., \& Esfandiarei, M. (2018). Executive function and quality of life in individuals with Marfan syndrome. Quality of Life Research, 27, 2057-2065. https://doi. org/10.1007/s11136-018-1859-7

Reiter-Purtill, J., Gerhardt, C. A., Vannatta, K., Passo, M. H., \& Noll, R. B. (2003). A controlled longitudinal study of the social functioning of children with juvenile rheumatoid arthritis. Journal of Pediatric Psychology, 28, 17-28. https://doi.org/10.1093/ jpepsy/28.1.17

Rolland, J. S. (1987). Family illness paradigms: Evolution and significance. Family Systems Medicine, 5, 482-503. https://doi.org/10.1037/h0089735

Rolland, J. S. (1999). Parental illness and disability: a family systems framework. Journal of Family Therapy, 21, 242-266. https://doi.org/10.1111/14676427.00118
Chronically ill adolescents within the family system 
Scherer, L. R., Arn, P. H., Dressel, D. A., Pyeritz, R. M. \& Haller, J. A. (1988). Surgical management of children and young adults with Marfan syndrome and pectus excavatum. Journal of Pediatric Surgery, 23, 1169-1172. https://doi.org/10.1016/s00223468(88)80335-x

Schoormans, D., Radonic, T., De Witte, P., Groenink, M., Azim, D., Lutter, R., Mulder, B. J., Sprangers, M. A., \& Zwinderman, A. H. (2012). Mental quality of life is related to a cytokine genetic pathway. PloS One, 7 ,
Agnieszka

Trawicka, Aleksandra LewandowskaWalter, Marta Bogdanowicz, Lidia WoźniakMielczarek, Dorota JanikowskaHołoweńko, Magdalena Bilicka-Siewert e45126. https://doi.org/10.1371/journal.pone.0045126

Seid, M., Huang, B., Niehaus, S., Brunner, H. I., \& Lovell, D. J. (2014). Determinants of health-related quality of life in children newly diagnosed with juvenile idiopathic arthritis. Arthritis Care \& Research, 66, 263-269. https://doi.org/10.1002/acr.22117

Szabała, B. (2009). Rodzina dziecka z cukrzyca [Family of a child with diabetes]. Lublin: Wydawnictwo Uniwersytetu Marii Curie-Skłodowskiej.

Tuszkiewicz-Misztal, E., Smolewska, E., Postępski, J., \& Olesińska, E. (2014). Reumatologia wieku rozwojowego [Rheumatology of the developmental age]. In I. Zimmermann-Górska (Ed.), Postępy reumatologii klinicznej [Advances in clinical rheumatology] (pp. 62-89). Warszawa: PZWL.

Vandvik, I. H. (1990). Mental health and psychosocial functioning in children with recent onset of rheumatic disease. Journal of Child Psychology and Psychiatry, 31, 961-971. https://doi.org/ 10.1111/j.1469-7610.1990.tb00837.x

Velvin, G., Bathen, T., Rand-Hendriksen, S., \& Geirdal, A. Ø. (2016). Satisfaction with life in adults with Marfan syndrome (MFS): associations with health-related consequences of MFS, pain, fatigue, and demographic factors. Quality of Life Research, 25, 1779-1790. https://doi.org/10.1007/ s11136-015-1214-1

Velvin, G., Wilhelmsen, J. E., Johansen, H., Bathen, T., \& Geirdal, A. Ø. (2019). Systematic review of quality of life in persons with hereditary thoracic aortic aneurysm and dissection diagnoses. Clinical Genetics, 95, 661-676. https://doi.org/10.1111/cge.13522

Ward, T. M., Sonney, J., Ringold, S., Stockfish, S., Wallace, C. A., \& Landis, C. A. (2014). Sleep disturbances and behavior problems in children with and without arthritis. Journal of Pediatric Nursing, 29, 321-328. https://doi.org/10.1016/j.pedn.2014.03.022

Wolańczyk, T. (2002). Zaburzenia emocjonalne i behawioralne u dzieci i mtodzieży szkolnej w Polsce [Emotional and behavioral disorders in children and adolescents in Poland]. Warszawa: Akademia Medyczna.

Woźniak-Mielczarek, L. (2017). Ocena układu krążenia u pacjentów z zespotem Marfana [Evaluation of cardiovascular system in patients with Marfan syndrome]. Unpublished doctoral dissertation. Gdansk: Gdansk Medical University.
Ziarko, M. (2014). Zmaganie się ze stresem choroby przewlektej [Coping with chronic illness]. Poznań: Wydawnictwo Naukowe Wydziału Nauk Społecznych UAM.

Zubrzycka, R. (2014). Uszkodzony gen. O problemach osób z mukowiscydozą i ich rodzin [Damaged gen. About the problems of people with cystic fibrosis and their families]. Dyskursy Pedagogiki Specjalnej, 15, 140-150. 